\title{
Metabolism of steroidal lactones by the fungus Corynespora cassiicola CBS 161.60 results in a mechanistically unique intramolecular ring-D cyclization resulting in $\mathbf{C}-14$ spiro-lactones
}

DOI:

10.1016/j.bbalip.2017.06.003

\section{Document Version}

Accepted author manuscript

Link to publication record in Manchester Research Explorer

\section{Citation for published version (APA):}

Hunter, A. C., Oni, Y. I., Dodd, H. T., Raftery, J., Gardiner, J. M., \& Uttley, M. (2017). Metabolism of steroidal lactones by the fungus Corynespora cassiicola CBS 161.60 results in a mechanistically unique intramolecular ringD cyclization resulting in C-14 spiro-lactones. Biochimica et Biophysica Acta - Molecular and Cell Biology of Lipids, 1862(9), 939-945. https://doi.org/10.1016/j.bbalip.2017.06.003

\section{Published in:}

Biochimica et Biophysica Acta - Molecular and Cell Biology of Lipids

\section{Citing this paper}

Please note that where the full-text provided on Manchester Research Explorer is the Author Accepted Manuscript or Proof version this may differ from the final Published version. If citing, it is advised that you check and use the publisher's definitive version.

\section{General rights}

Copyright and moral rights for the publications made accessible in the Research Explorer are retained by the authors and/or other copyright owners and it is a condition of accessing publications that users recognise and abide by the legal requirements associated with these rights.

\section{Takedown policy}

If you believe that this document breaches copyright please refer to the University of Manchester's Takedown Procedures [http://man.ac.uk/04Y6Bo] or contact uml.scholarlycommunications@manchester.ac.uk providing relevant details, so we can investigate your claim.

\section{OPEN ACCESS}




\title{
Accepted Manuscript
}

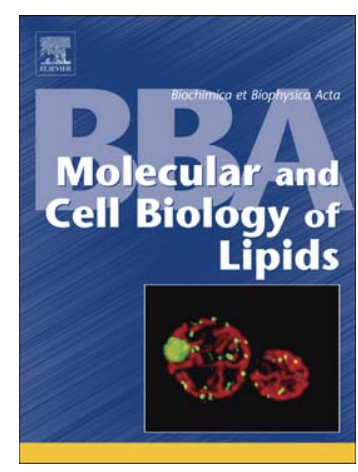

A. Christy Hunter, Yewande Inatimi Oni, Howard T. Dodd, James Raftery, John M. Gardiner, Megan Uttley

\author{
PII: $\quad$ S1388-1981(17)30107-5 \\ DOI: $\quad$ doi: $10.1016 /$ j.bbalip.2017.06.003 \\ Reference: $\quad$ BBAMCB 58159 \\ To appear in: $\quad$ BBA - Molecular and Cell Biology of Lipids \\ Received date: 22 February 2017 \\ Revised date: $\quad 26$ May 2017 \\ Accepted date: 7 June 2017
}

Please cite this article as: A. Christy Hunter, Yewande Inatimi Oni, Howard T. Dodd, James Raftery, John M. Gardiner, Megan Uttley, Metabolism of steroidal lactones by the fungus Corynespora cassiicola CBS 161.60 results in a mechanistically unique intramolecular ring-D cyclization resulting in C-14 spiro-lactones, BBA - Molecular and Cell Biology of Lipids (2017), doi:10.1016/j.bbalip.2017.06.003

This is a PDF file of an unedited manuscript that has been accepted for publication. As a service to our customers we are providing this early version of the manuscript. The manuscript will undergo copyediting, typesetting, and review of the resulting proof before it is published in its final form. Please note that during the production process errors may be discovered which could affect the content, and all legal disclaimers that apply to the journal pertain. 


\section{Metabolism of steroidal lactones by the fungus Corynespora} cassiicola CBS 161.60 results in a mechanistically unique intramolecular ring-D cyclization resulting in $\mathrm{C}-14$ spiro-lactones

A. Christy Hunter, ${ }^{1 *}$ Yewande Inatimi Oni, ${ }^{2}$ Howard T. Dodd, ${ }^{3}$ James Raftery, ${ }^{4}$ John M. Gardiner, ${ }^{5}$ Megan Uttley, ${ }^{4,5}$

De Montfort University, Leicester School of Pharmacy, The Gateway, Leicester, LE1 9BH ${ }^{1}$, UK. University of Nottingham, School of Pharmacy, Nottingham, NG7 2RD, UK². University of Brighton, School of Pharmacy and Biomolecular Sciences, Huxley Building, Lewes Road, Brighton. BN2 4GJ, UK ${ }^{3}$. University of Manchester, School of Chemistry University of Manchester, Oxford Road, Manchester, M13 9PL ${ }^{4}$, UK. Manchester Institute of Biotechnology, 131 Princess Street, Manchester, M1 7DN, UK 5 .

* Corresponding author. Tel.: +44 (0)116 2506546

E-mail address christy.hunter@dmu.ac.uk

Keywords : Corynespora cassiicola; Lactone, Spiro-carbon; Steroid; Cyclization, Transesterification. 


\begin{abstract}
The fungus Corynespora cassiicola metabolises exogenous steroids in a unique and highly specific manner. Central to this, is the ability of this organism to functionalise substrates (androgens, progestogens) at the highly stereochemically hindered $8 \beta$-position of the steroid nucleus. A recent study has identified that $8 \beta$-hydroxylation occurs through inverted binding in a 9 $\alpha$-hydroxylase. In order to discern the metabolic fate of more symmetrical molecules, we have investigated the metabolism of a range of steroidal analogues functionalised with ring-D lactones, but differing in their functional group stereochemistry at carbon-3. Remarkably, the $3 \alpha$-functionalised steroidal lactones underwent a mechanistically unique two step intramolecular cyclisation resulting in the generation of a ring-D spiro-carbolactone. This rapid rearrangement initiated with hydroxylation at carbon 14 followed by transesterification, resulting in ring contraction with formation of a butyrolactone at carbon-14. Remarkably this rearrangement was found to be highly dependent on the stereochemistry at carbon-3, with the $\beta$-analogues only undergoing $9 \alpha$-hydroxylation. The implications of these findings and their mechanistic bases are discussed.
\end{abstract}




\section{Introduction}

Spiro-carbon containing compounds are formed in a range of different organisms that include bacteria, yeast, fungi, plants and insects [1-4]. These secondary metabolites are generated through polyketide, as well as dual shunt pathways [5]. They are structurally diverse and frequently have important biological activity [6-8]. Here we report for the first time, the generation of a 5-membered steroidal ring-D spiro-lactone, through a novel biocatalytic pathway by the fungus Corynespora cassiicola. This organism is unique amongst fungi, in that it can monohydroxylate androgens and progestogens at the highly hindered $8 \beta$ position on the steroid nucleus [9-11]. Mechanistically, the $8 \beta$-hydroxylation of androgens and progestogens occurs through inverted binding within an endogenous $9 \alpha$-hydroxylase [9]. In contrast to many steroidal transformations by fungi [12] monohydroxylations observed to date with this organism predominate with axial stereochemistry, the precise position of attack being dependent on the type of steroid nucleus [9-11]. For example, androgens undergo axial attack both above and below the plane of the steroidal ring system. In contrast, progestogens must have C-17 $\alpha$ functionality (alcohol or epoxide) to undergo enzymatic attack at the $8 \beta$ position.

In order to further reveal the factors determining steroid metabolism by this organism, we have investigated ring-D steroidal lactones which differ in functional group (alcohol, acetate) stereochemistry at C-3. Previous studies on the metabolic fate of these molecules by the filamentous fungus Aspergillus tamarii [13] demonstrated that these structural architectures can be hydroxylated in all four possible binding orientations within the steroid hydroxylase, with monohydroxylation occurring at both axial and equatorial positions. This flexibility of steroidal lactone/hydroxylase binding orientation is facilitated by increased symmetry imparted by having a six-membered ring-D. Structurally this results in the C-17 
carbonyl group being transposed in to a more central position in the plane of the steroid [14] nucleus, as compared to steroids with a C-17 keto architecture.

The metabolism of the steroidal lactones by Corynespora cassiicola has revealed a unique rearrangement reaction (Fig.1). This is mechanistically (Fig.2) based on a two-step enzyme catalysed transformation resulting in C-14 steroidal spiro-lactones, the formation of which has highly specific stereochemical requirements.

\section{Materials and methods}

\subsection{Chemicals and Reagents}

Steroidal lactones 1-4 were synthesized [14] and analysed as previously described $[13,15]$. They were all found to be in excess $99 \%$ purity following elemental analysis, $3 \alpha$-Acetoxy17a-oxa-D-homo-5 $\alpha$-androstan-17-one 1 [found: C, 72.35; $\mathrm{H}, 9.36 . \mathrm{C}_{21} \mathrm{H}_{32} \mathrm{O}_{4}$ requires $\mathrm{C}$, 72.38; H, 9.26\%]; 3 $\alpha$-Hydroxy-17a-oxa-D-homo-5 $\alpha$-androstan-17-one 2 [found: C, 74.14; H,

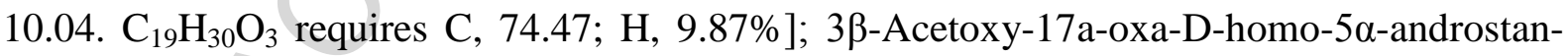

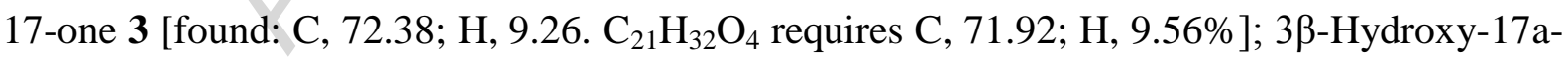
oxa-D-homo-5 $\alpha$-androstan-17-one 4 [found: $\mathrm{C}, 73.05, \mathrm{H}, 10.22 \mathrm{C}_{19} \mathrm{H}_{30} \mathrm{O}_{3} \cdot 0.33 . \mathrm{H}_{2} \mathrm{O}$ requires C73.02; H 9.9\%]. All other chemicals and reagents were supplied by the Aldrich Chemical Company (UK). Solvents were of analytical grade; light petroleum ether refers to the fraction with a boiling point $60-80{ }^{\circ} \mathrm{C}$. Silica for column chromatography was Merck 9385 and TLC was performed with Macherey-Nagel Alugram ${ }^{\circledR}$ SIL G/UV 254

\subsection{Microorganism}


Corynespora cassiicola CBS 161.60 was obtained from the collection at the Centraalbureau voor Schimmelcultures (Ned). Stock cultures were grown on potato dextrose agar (Oxoid, UK) slopes (3 days) and maintained at $4^{\circ} \mathrm{C}$ until use. Steroid transformation studies were carried out in 3\% malt extract medium (Oxoid, UK).

\subsection{Conditions of cultivation and transformation}

Spores were transferred aseptically in a containment level 2 biological safety cabinet into $500 \mathrm{ml}$ Erlenmeyer flasks containing $300 \mathrm{ml}$ of sterile media and were incubated for $72 \mathrm{~h}$ at $25{ }^{\circ} \mathrm{C}$. The cultures were shaken at $180 \mathrm{rpm}$ on an orbital shaker. Aliquots $(5 \mathrm{ml})$ from the seed flask were transferred aseptically to 5 flasks and grown for a further $72 \mathrm{~h}$ as above, at the end of which the fungus is in log phase growth. After this time period, steroid dissolved in dimethylformamide (DMF) was evenly distributed between the flasks $(1 \mathrm{mg} / \mathrm{mL})$ under sterile conditions and incubated for a further 5 days after which the metabolites were extracted from the broth.

\subsection{Extraction and separation of metabolites}

The fungal mycelium was separated from the broth by filtration under vacuum. Following completion, the mycelium was rinsed with ethyl acetate $(0.5 \mathrm{~L})$ to ensure the entire available steroid was removed. The mycelial broth was then extracted twice with ethyl acetate (1.5 L). The organic extract was dried over anhydrous sodium sulfate and the solvent evaporated in vacuo to give a gum. This gum was adsorbed onto silica and chromatographed on a column of silica; the steroidal metabolites were eluted with increasing concentrations of ethyl acetate in light petroleum ether. The solvent was collected in aliquots $(10 \mathrm{ml})$ and analysed by thin layer chromatography (TLC) to identify the separated metabolite fractions. The solvent systems used for running the TLC plates were 50:50 light petroleum ether in 
ethyl acetate or pure ethyl acetate. A 50:50 sulfuric acid in methanol spray was used to develop the TLC plates.

\subsection{Analysis and identification of metabolites}

Characteristic shift values $[16,17]$ in the ${ }^{1} \mathrm{H}$ and ${ }^{13} \mathrm{C}$ NMR spectra from the starting compounds were used to determine metabolite structure and used in combination with DEPT analysis to identify the nature of the carbon (Tables 1 and 2). Spectra were recorded on a B400 Bruker Advance III $400 \mathrm{MHz}$ spectrometer, all samples were analysed in deuteriochloroform using tetramethylsilane as the internal standard. Infra-red spectra were recorded directly on a Nicolet avatar 320 FT-IR fitted with a Smart Golden Gate ${ }^{\circledR}$.

\subsection{Time course experiment}

Experimental conditions were identical to those in section 2.3 except that steroids (600mg) dissolved in DMF (6 mL) was evenly distributed between 6 flasks (each containing $100 \mathrm{~mL}$ media) $(\mathbf{1}, \mathbf{2}, \mathbf{3}, \mathbf{4})$. One flask was harvested after $12 \mathrm{~h}$, then one every $24 \mathrm{~h}$ from the initiation of the experiment. These were extracted as in section 2.4. Following $6 \mathrm{~h}$ under high vacuum, the product ${ }^{1} \mathrm{H}$ NMR spectrum was determined in $\mathrm{CDCl}_{3}$ to confirm the presence and steroidal nature of the extracts.

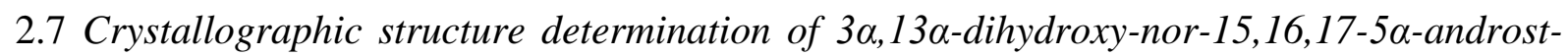
$14 \alpha$-carbolactone 5

$\mathrm{C}_{19} \mathrm{H}_{30} \mathrm{O}_{4}, M_{r}: 322.43$, orthorhombic space group $P 2{ }_{1} 2_{1} 2_{1}$ (No.19), $a=6.0682(3), b=$ 16.4779(8), $c=19.0484(4) \AA, \alpha=\beta=\gamma=90^{\circ}, V=1735.06(14) \AA^{3}, Z=4, D_{\text {calc }}=1.234 \mathrm{mg} / \mathrm{m}^{3}$, $u=0.679 \mathrm{~mm}^{-1}, F(000) 704$. Data were collected using a crystal of size $0.25 \mathrm{~mm} \times 0.21 \mathrm{~mm} \times$ $0.09 \mathrm{~mm}$ on a Bruker APEX CCD X-ray diffractometer by using graphite monochromated, 
MoK $\alpha$ radiation $($ wavelength $=0.71073 \AA$ ). A total of 5084 reflections were collected for 3.70 $<\theta<72.19^{\circ}$ and $-7 \leq \mathrm{h} \leq 4,-20 \leq \mathrm{k} \leq 12,-18 \leq 1 \leq 2$. There were 5084 independent reflections and 2859 reflections with $I>2 \sigma(I)$ were used in the refinement. No absorption correction was applied. The structures were solved by direct methods and refined by fullmatrix least-squares on all $\mathrm{F}_{0}^{2}$ data using SHELXL-97. The diagram used ORTEP-3 for windows. The final $R$ indices (all data) were $[\mathrm{I}>2 \sigma(\mathrm{I})] R 1=0.035, \mathrm{w} R 2=0.09$ and $R$ indices (all data) $R 1=0.037, \mathrm{w} R 2=0.092$. The goodness-of-fit on $F^{2}$ was 1.070 and the largest difference peak and hole was 0.21 and $-0.20 \mathrm{e}^{-3}$. The crystallographic data have been deposited with the Cambridge Crystallographic Data Centre, CCDC 1532852 contains the supplementary crystallographic data for this paper for compound 5. These data can be obtained free of charge via www.ccdc.cam.ac.uk/data_request/cif, or by emailing data_ request@ccdc.cam.ac.uk, or by contacting The Cambridge Crystallo- graphic Data Centre, 12, Union Road, Cambridge CB2 1EZ, U.K. Fax: +44 1223 336033.”

\section{Results}

\subsection{Products isolated following transformation}

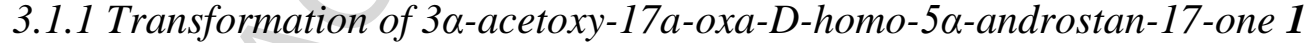

Starting material 1 (127 mg, 8.5\%) was recovered from the chromatography column with $30 \%$ ethyl acetate in light petroleum ether, comparison of the ${ }^{1} \mathrm{H}$ and ${ }^{13} \mathrm{C}$ NMR spectra to an authentic sample confirmed structural identity [15]. Elution with 55\% ethyl acetate in light petroleum ether afforded a product of hydrolysis, $3 \alpha$-hydroxy-17a-oxa-D-homo- $5 \alpha$-androstan17-one 2 (107 mg, 7\%). Comparison of this structure to the ${ }^{1} \mathrm{H}$ and ${ }^{13} \mathrm{C}$ NMR spectra of an

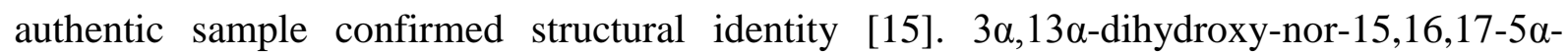
androst-14 $\alpha$-carbolactone 5 (353mg, 24\%) was isolated from the chromatography column at a concentration of $60 \%$ ethyl acetate in light petroleum ether and was crystalized from ethyl 
acetate in light petroleum ether as needles m.p. 243-246 ${ }^{\circ} \mathrm{C}$ (found: $\mathrm{C}, 70.12 ; \mathrm{H}, 9.48$ $\mathrm{C}_{19} \mathrm{H}_{30} \mathrm{O}_{4}$ requires $\left.\mathrm{C}, 70.76, \mathrm{H}, 9.38 \%\right) ; \mathrm{IR}_{\text {vmax }} \mathrm{cm}^{-1}=3405 \mathrm{br}, 1751 ;{ }^{1} \mathrm{H} \mathrm{NMR}\left(\mathrm{CDCl}_{3}\right) 0.73$ (3H, s, 19-H), 1.17 (3H, s, 18-H), $4.40(1 \mathrm{H}, \mathrm{d}, J=2 \mathrm{~Hz}, 3 \beta-\mathrm{H})$

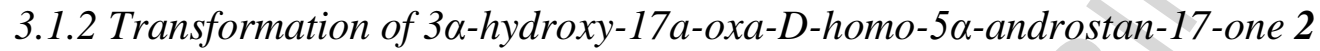

Starting material 2 (91 mg, 18\%) was recovered from the chromatography column with 55\% ethyl acetate in light petroleum ether, comparison of the ${ }^{1} \mathrm{H}$ and ${ }^{13} \mathrm{C}$ NMR spectra to an authentic sample confirmed structural identity [15]. Elution with $60 \%$ ethyl acetate in light

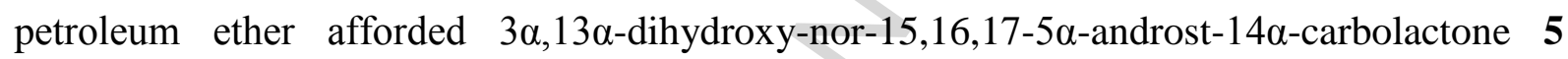
(130mg, 26\%). Comparison of the ${ }^{1} \mathrm{H}$ and ${ }^{13} \mathrm{C}$ NMR spectra of this product with that of an authentic sample confirmed its' structure. $3 \alpha, 9 \alpha$-Dihydroxy-17a-oxa-D-homo-5 $\alpha$-androstan17-one (6) eluted from the chromatography column at $80 \%$ ethyl acetate in petroleum ether as a gum (HRMS ESI: Calc for $\mathrm{M}+\mathrm{Na}^{+}: 345.203$ obsd. 345.204$) ; \mathrm{IR}_{v \max } \mathrm{cm}^{-1}=3398 \mathrm{br}$ and 1792; ${ }^{1} \mathrm{H}$ NMR $\left(\mathrm{CDCl}_{3}\right) 0.88(3 \mathrm{H}, \mathrm{s}, 19-\mathrm{H}), 1.30(3 \mathrm{H}, \mathrm{s}, 18-\mathrm{H}), 4.02(1 \mathrm{H}, \mathrm{t}, \mathrm{J}=2.7 \mathrm{~Hz}, 3 \beta-\mathrm{H})$.

\subsubsection{Transformation of $3 \beta$-acetoxy-17a-oxa-D-homo-5a-androstan-17-one 3}

Starting material 3 (194 mg, 19\%\%) was recovered from the chromatography column with $30 \%$ ethyl acetate in light petroleum ether, comparison of the ${ }^{1} \mathrm{H}$ and ${ }^{13} \mathrm{C}$ NMR spectra to an authentic sample confirmed structural identity $[13,14]$. Elution with $45 \%$ ethyl acetate in petroleum ether afforded 9 $\alpha$-hydroxy-17a-oxa-D-homo-5 $\alpha$-androstan-3,17-dione 8 (214mg, $21 \%$ ) which, crystalized from ethyl acetate in light petroleum ether as needles m.p. $216{ }^{\circ} \mathrm{C}$ with decomposition. (found: $\mathrm{C}, 70.89 ; \mathrm{H}, 9.22 \mathrm{C}_{19} \mathrm{H}_{28} \mathrm{O}_{4}$ requires $\mathrm{C}, 71.22, \mathrm{H}, 8.81 \%$ ); (HRMS ESI: Calc. for $\mathrm{M}+\mathrm{Na}^{+}: 343.187$ obsd. 343.187 ); $\mathrm{IR}_{v \max } \mathrm{cm}^{-1}=3411,1703 \mathrm{br} ;{ }^{1} \mathrm{H} \mathrm{NMR}$ $\left(\mathrm{CDCl}_{3}\right) 1.10(3 \mathrm{H}, \mathrm{s}, 19-\mathrm{H}), 1.33(3 \mathrm{H}, \mathrm{s}, 18-\mathrm{H}) .3 \beta, 9 \alpha-D$ ihydroxy-17a-oxa-D-homo-5 $\alpha-$ androstan-17-one 7 (396mg, 39\%) eluted at a concentration of 65\% ethyl acetate in petroleum 
ether as a gum (HRMS ESI: Calc. for $\mathrm{M}+\mathrm{Na}^{+}: 345.203$ obsd. 345.204$) ; \mathrm{IR}_{v \max } \mathrm{cm}^{-1}=3398 \mathrm{br}$ and 1792; ${ }^{1} \mathrm{H}$ NMR $\left(\mathrm{CDCl}_{3}\right) 0.90(3 \mathrm{H}, \mathrm{s}, 19-\mathrm{H}), 1.31(3 \mathrm{H}, \mathrm{s}, 18-\mathrm{H}), 3.60(1 \mathrm{H}, \mathrm{tt}, \mathrm{J}=5 \mathrm{~Hz}, \mathrm{~J}=$ $9 \mathrm{~Hz}, 3 \alpha-\mathrm{H})$.

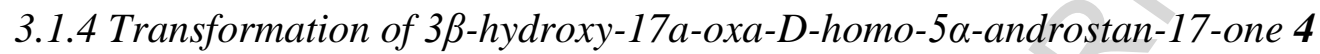

Starting material 4 (400 mg, 40\%) was recovered from the chromatography column with $40 \%$ ethyl acetate in light petroleum ether, comparison of the ${ }^{1} \mathrm{H}$ and ${ }^{13} \mathrm{C}$ NMR spectra to an authentic sample confirmed structural identity $[13,14]$. Elution with $60 \%$ ethyl acetate in petroleum ether afforded 3 $\beta, 9 \alpha$-dihydroxy-17a-oxa-D-homo-5 $\alpha$-androstan-17-one 8 (76mg, $8 \%) 7$ which was identified by comparison of the spectral data to that of an authentic sample.

\subsection{Identification of metabolites}

Transformation of $\mathbf{1}$ yielded two products of transformation. Comparison of the ${ }^{1} \mathrm{H}$ NMR spectrum of the first product to that of the starting material demonstrated loss of the acetate signal at $2.06 \mathrm{ppm}(3 \mathrm{H}, \mathrm{s})$ and an upfield shift for the $3 \beta$-proton, indicating that hydrolysis had taken place. This was further supported by the product ${ }^{13} \mathrm{C}$ NMR which was devoid of the C-20 (169.88 ppm) and C-21 (21.51 ppm) resonance signals. All of these product signals were consistent with that of an authentic sample of $3 \alpha$-hydroxy-17a-oxa-Dhomo-5 $\alpha$-androstan-17-one 2.

The second product of transformation was identified as $3 \alpha, 13 \alpha$-Dihydroxy-nor15,16,17-5 $\alpha$-androst-14 $\alpha$-carbolactone 5. This molecule, in comparison to the starting material, had undergone hydrolysis at $\mathrm{C}-3$, with loss of all acetate signals vide supra. Comparison of the product $5{ }^{1} \mathrm{H}$ NMR spectrum to that of $\mathbf{2}$ revealed a significant shift $(0.12$ ppm) upfield for the 18-methyl resonance possibly suggesting loss of the ethereal oxygen present in the ring-D lactone of 2 . The ${ }^{13} \mathrm{C}$ NMR spectrum of the product further supported 
loss of the 6-ring ethereal oxygen, this was demonstrated by a new upfield shift (10.18 ppm) in the ${ }^{13} \mathrm{C}$ NMR spectrum, resulting in a resonance value of $73.31 \mathrm{ppm}$. This was consistent with the presence of a hydroxyl group thus indicating opening of the ring-D lactone and formation of a new carbon skeleton. A new signal in the product spectrum at $93.17 \mathrm{ppm}$ was consistent with the presence of a spiro-carbon [18] as was the downfield shift (4.63 ppm) for carbon 8 . This suggested that a more thermodynamically stable 5-ring lactone had been formed; this was fully supported by the downfield shift of $6.04 \mathrm{ppm}$ for the C-17 nonprotonated carbon. Elemental analysis and X-ray crystallography fully supported the proposed structure of 5 (Fig. 3)

Two products of transformation were isolated following incubation of compound 2. The first metabolite was identified as $3 \alpha, 13 \alpha$-dihydroxy-nor-15,16,17-5 $\alpha$-androst-14 $\alpha$ carbolactone 5 by comparison of its ${ }^{1} \mathrm{H}$ and ${ }^{13} \mathrm{C}$ NMR spectra with that of an authentic sample. The second product isolated demonstrated a significant downfield shift in the ${ }^{1} \mathrm{H}$ NMR for the 19-methyl group of $0.13 \mathrm{ppm}$. Absence of any new signals in this spectrum suggested hydroxylation at a methyne proton such as C-5 or C-9 generating a non-protonated quaternary resonance. Lack of observed downfield shift for the $3 \beta$-proton indicated hydroxylation at the axial C-9 position of the steroid. This notion was further supported by comparison of the product ${ }^{13} \mathrm{C}$ NMR spectrum with that of the starting material where all $\beta$ carbons to C-9 had undergone downfield shifts C-8 (2.02 ppm), C-10 (4.53 ppm) and C-11 (4.71 ppm) and $\gamma$-carbons upfield shifts were observed for C-5 (8.11 ppm), C-7 (2.79 ppm) and C-14 (7.86 ppm), all of which supported the proposed structure of $3 \alpha, 9 \alpha$-dihydroxy-17aoxa-D-homo-5 $\alpha$-androstan-17-one 6 as did accurate mass measurement.

The first product of biotransformation following incubation of $\mathbf{3}$ was identified as $3 \beta, 9 \alpha$-dihydroxy-17a-oxa-D-homo-5 $\alpha$-androstan-17-one 7. The ${ }^{1} \mathrm{H}$ NMR spectrum of this 
compound demonstrated a downfield shift $(0.1 \mathrm{ppm})$ for the 19 -methyl signal in the absence of any new resonance signals, this suggested hydroxylation at C-5 or C-9. The $3 \alpha-\mathrm{H}$ signal at $4.69 \mathrm{ppm}(3 \mathrm{H}, \mathrm{tt})$ present in the starting material ${ }^{1} \mathrm{H}$ NMR spectrum had undergone an upfield shift $(1.0 \mathrm{ppm})$ to $3.60 \mathrm{ppm}(1 \mathrm{H}, \mathrm{tt})$. This coupled with the loss of the resonance signal at 2.02 ppm from the product ${ }^{1} \mathrm{H}$ NMR spectrum indicated that the acetate group had been hydrolysed, resulting in a $3 \beta$-hydroxyl group. This structural change was further confirmed by absence of the C-20 (171.60 ppm) and C-21 (21.45 ppm) from the product ${ }^{13} \mathrm{C}$ NMR spectrum. Hydroxylation at C-9 was confirmed with $\beta$-carbon downfield shifts for C-8 (2.07 ppm), C-10 (4.64 ppm) and C-11 (2.98 ppm) and $\gamma$-carbon upfield shifts for C-5 (8.08 ppm), C-12 (10.40 ppm) and C-14 (6.27 ppm) all of which were consistent with the proposed structure. This was also fully supported by elemental analysis and accurate mass measurement.

The second product of biotransformation was identified as $9 \alpha$-hydroxy-17a-oxa-Dhomo-5 $\alpha$-androstan-3,17-dione 8. The ${ }^{1} \mathrm{H}$ NMR spectrum for this product did not contain resonance signals consistent with the presence of the $3 \alpha-\mathrm{H}(1 \mathrm{H}, \mathrm{tt})$. This was confirmed in the product ${ }^{13} \mathrm{C}$ NMR resonance where the acetate signals at C-20 (171.60 ppm) and C-21 (21.45 ppm) and been replaced by a non-protonated carbon resonance signal at $211.80 \mathrm{ppm}$. Hydroxylation at carbon 9 was confirmed by $\beta$-carbon downfield shifts for C8 (2.02 ppm), C10 (4.71 ppm) and C-11 (2.65 ppm) and $\gamma$-carbon upfield shifts for C-1 (2.11 ppm), C-5 (4.03 ppm), C-12 (10.52 ppm) and C-14 (8.10 ppm). Accurate mass measurement also fully supported the proposed structure.

Transformation of 4 resulted in the isolation of $3 \beta, 9 \alpha$-dihydroxy-17a-oxa-D-homo-5 $\alpha$ androstan-17-one 7. The structure of this compound was confirmed by comparison to that of an authentic sample. 


\subsection{Determination of metabolic pathway for compounds 1, 2, 3 and 4}

${ }^{1} \mathrm{H}$ NMR was used to follow the steroidal transformation $[9,15,19,20]$ and thus enable the determination of the time sequence to the formation of the individual metabolites isolated in this study.

Following 24 hours incubation of $\mathbf{1}$, complete hydrolysis of the $3 \alpha$-acetate group to the $3 \alpha$-alcohol 2 occurred. This was demonstrated by an upfield shift in the $3 \beta$-proton resonance signal $(1 \mathrm{H}, \mathrm{t})$ from $5.1 \mathrm{ppm}$ in the starting material 1 to $4.06 \mathrm{ppm}(1 \mathrm{H}, \mathrm{t})$ in 2 . Formation of the spiro-lactone 5 was first observed at the 48 hour time point. This was identified in the ${ }^{1} \mathrm{H}$ NMR spectrum with the presence of new methyl resonances at $0.73 \mathrm{ppm}(19-\mathrm{H})$ and 1.18 ppm (18-H) respectively which are consistent with formation of the molecular structure of $\mathbf{5}$.

Transformation of $\mathbf{2}$ resulted in formation of the spiro-lactone $\mathbf{5}$ as well as the $9 \alpha$ hydroxy lactone 6. Examination of the ${ }^{1} \mathrm{H}$ NMR spectrum at 48 hours revealed signals consistent with 5 (vide supra). The presence of compound $\mathbf{6}$ was identified by a downfield resonance signal, in comparison to the starting material, for the 19 -methyl group at $0.88 \mathrm{ppm}$.

Transformation of $\mathbf{3}$ demonstrated key structural changes to the starting material at the $48 \mathrm{hr}$ time point. Hydrolysis of the $3 \beta$-acetate group was confirmed by the presence of a new resonance signal for the $3 \alpha$-proton at $3.60 \mathrm{ppm}(1 \mathrm{H}, \mathrm{tt})$ and a new 19-methyl resonance at $0.90 \mathrm{ppm}(3 \mathrm{H}, \mathrm{s})$ confirmed the formation of 7. Formation of $\mathbf{8}$ was confirmed by the presence of the 19-methy resonance signal at $1.10 \mathrm{ppm}$ and this was present at the 48 hour time point. Hydroxylation of $\mathbf{4}$ at carbon-9 was observed following 48 hours with the presence of a new 19-methyl signal at $0.90 \mathrm{ppm}$.

\section{Discussion}


Formation of the spiro-lactone $\mathbf{5}$ is the first example of a hydroxylase catalysed transesterification of a steroid in any organism. The carbon skeleton generated is novel and mechanistically insightful (Fig. 2 and Fig. 3), especially as spiro-carbons are a rare metabolic phenomenon within xenobiotic pathways $[21,22]$. The unique bimodal base catalysed transformation initiates after 48 hours incubation with hydroxylation at C-14 alpha, a position on the steroid nucleus at the trans C/D ring junction (Fig. 2, Intermediates A-D). Opening of the ring-D lactone in the substrate presumably occurred through the activity of a lactonohydrolase, a transformation previously reported on exogenous steroids by fungi [23]. Ring opening of the lactone facilitates rearrangement through transesterification (Fig. 2, Intermediates $\mathrm{C}$ and $\mathrm{D}$ ) resulting in the formation of the spiro-butyrolactone $\mathbf{5}$.

The in situ generation of compound $\mathbf{5}$ was supported by the timed experiments where samples for ${ }^{1} \mathrm{H}$ NMR did not undergo column chromatography. The spectra of these samples contained the 19 -methyl resonance $(0.73 \mathrm{ppm})$ which was consistent with the rearrangement of 5 .

Furthermore, from these experiments there was no spectroscopic evidence for 18methyl downfield shift values of $0.1 \mathrm{ppm}$ that would have been consistent with the presence of the $14 \alpha$-hydroxylation product, with the 6-membered ring-D lactone in either open or closed constitution [23,24]. It is of note that some species of Corynespora cassiicola do produce macrolactone structures such as octa and deca-lactones [25-27], but in contrast to our reported mechanism, these lactones are polyketide derived secondary metabolites.

The mechanistic basis for the biosynthetic formation of austinol, a fungal meroterpenoid from Aspergillus nidulans, which contains spiro-ring formation was recently reported [28]. The mechanism leading to the spiro-carbon in this secondary metabolite had distinct similarities to our observed biosynthetic transformation. The rearrangement initiated through hydroxylation (albeit at a $\beta$-proton) followed by ring contraction (7 to 6 membered 
ring), but differed in the final step, which required dehydrogenation resulting in double bond formation to the spiro-ring. It is of note that an alternative double bond participated radical rearrangement has been proposed [29].

In the case of formation of the spiro-ring in $\mathbf{5}$, one would expect little difference in the thermodynamic stability between the 5- and 6-ring lactones, with the potential for rapid interconversion between them being supported by X-ray crystallography (where C-13 hydroxyl is $2.948 \AA$ from the five membered ring lactone, Fig. 3). In spite of this, only the five membered spiro-ring-D structure was observed. The prevalence of this may in part be due to the favoured twist chair conformation of the six membered lactone (Fig. 4a) and the favourable kinetic preorganization (Fig. 4b) it affords formation of the five membered lactone. This may, in part, explain the observed cyclisation to the 5-ring lactone $\mathbf{5}$ in comparison to the 6-membered counterpart [30,31].

Hydroxylation at C-14 and subsequent rearrangement of the lactone demonstrated a strict stereospecific requirement for the presence of a $3 \alpha$-hydroxyl group. In contrast, the $3 \beta$ hydroxylactones only underwent monohydroxylation at the C-9 $\alpha$ position. This suggests that

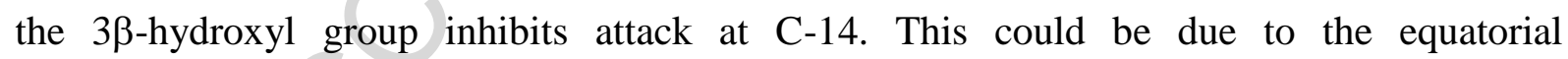
stereochemistry of this functional group physically extending the distance of the steroid $14 \alpha-$ proton away from active site, resulting in the $9 \alpha$-proton being positionally favoured for attack. In light of this, it could reasonably be argued that a single enzyme handles the respective $3 \alpha-$ and $3 \beta$-hydroxy steroidal lactones, as both structures underwent hydroxylation at carbon-9, but only the alpha alcohols underwent rearrangement. This would be consistent with previous studies that have indicated a high degree of structural flexibility, with both androgens and progestogens being hydroxylated at C-9 $\alpha$ by this organism [9]. Only future studies with isolation and structural elucidation of the responsible hydroxylase(s) will provide a definitive answer. 9 $\alpha$-Hydroxylation is a pharmaceutically important transformation [32] which 
facilitates intermediate compounds for $9 \alpha$-halogenated corticosteroids [33] and 9,11-dehydro systems for 11-keto steroids [34]. The novel spiro-lactone structure may also be of pharmaceutical interest, as drugs with ring-D lactones for example, spironolactone and eplerenone are already in clinical use for treatment of cardiac disease $[35,36]$ and potentially new applications in conditions such as HIV are on the horizon [37]. 


\section{References}

[1] J. Yaegashi, J. Romsdahl, Y-M. Chiang, C. C. C. Wang, Genome mining and molecular characterization of the biosynthetic gene cluster of a diterpenic meroterpenoid, 15deoxyoxalicine B, in Penicillium canescens, Chem. Sci., 6 (2015) 6537-6544

[2] S-G Ma, R-M Gao, Y-H Li, J-D Jiang, N-B Gong, L. Li, Y. Lü, W-Z Tang, Y-B. Liu, J. Qu, H-N Lü, Y. Li, S-S Yu, Antiviral spirooliganones A and B with unprecedented skeletons from the roots of Illcium oligandrum, Org. Lett., 15 (2013) 4450-4453

[3] Y. Zheng, S-W Zhang, H-J Cong, Y-J Huang, L-J Xuan, Caesalminaxins A-L, Cassane diterpenoids from the seeds of Caesalpina minax, J. Nat. Prod., 76 (2013) 2210-2218

[4] P. Lümmen, J. Khajehali, K. Luther, T. V. Leeuwen, The cyclic keto-enol insecticide spirotetramat inhibits insect and spider mite acetyl-CoA carboxylases by interfering with the carboxyltransferase partial reaction, Insect Biochem. Mol. Biol., 55 (2014) 1-8

[5] C. Darsih, V. Prachyawarakorn, S. Wiyakrutta, C. Mahidol, S. Ruchirawat, P. Kittakoop, Cytotoxic metabolites from the endophytic fungus Penicillium chermesinum: discovery of a cysteine-targeted Michael acceptor as a pharmacophores for fragment-based drug discovery, bioconjugation and click reactions, RSC Adv. 5 (2015) 70595-70603

[6] Y. Tsunematsu, N. Ishikawa, D. Wakana, Y. Goda, H. Noguchi, H. Moriya, K. Hotta, K. Watanabe, Distinct mechanisms for spiro-carbon formation reveal biosynthetic pathway crosstalk, Nat. Chem. Biol., 9 (2013) 818-825 
[7] C. R. Gray, J. F. Sanz-Cervera, L. A. Silks, R. M. Williams, Studies on the biosynthesis of asperparaline A: Origin of the spirosuccinimide ring system, J. Am. Chem. Soc., 125 (2003) $14692-14693$

[8] E. Wendt-Pienkowski, Y. Huang, J. Zhang, B. Li, H. Jiang, H. Kwon, C. R. Hutchinson, B. Shen, Cloning, sequencing, analysis and heterologous expression of the fredericamycin biosynthetic gene cluster from Streptomyces griseus, J. Am. Chem. Soc., 127 (2005) 1644216452

[9] A. C. Hunter, S.-J. Rymer, C. Dedi, H. T. Dodd, Q. C. Nwozor, S. M. Moghimi. Transformation of structurally diverse steroidal analogues by the fungus Corynespora casiicola CBS 161.60 results in generation of $8 \beta$-monohydroxyalated metabolites with evidence in favour of $8 \beta$-hydroxylation through inverted binding in the $9 \alpha$-hydroxylase. Biochim. Biophys. Acta Mol. Cell Biol. Lipid 1811 (2011) 1054-1061

[10] K. Tori, E. Kondo. 8 $\beta$-hydroxylation of Reichstein's substances by microorganism, Tetrahedron Lett. 10 (1963) 645-650

[11] D. Krischenowski, K. Kieslich, Two novel microbial conversion products of progesterone derivatives, Steroids, 58 (1993) 278-281

[12] N. Nassiri-Koopaei, M. Faramarzi, Recent developments in fungal transformation of steroids, Biocat. Biotrans., 33 (2015) 1-28

[13] A. C. Hunter, H. Bergin-Simpson, Distinct metabolic handling of 3 $\beta$-hydroxy-17a-oxaD-homo-5 $\alpha$-androstan-17-one by the filamentous fungus Aspergillus tamarii KITA: evidence 
in support of steroid/hydroxylase binding hypothesis, Biochim. Biophys. Acta, 1771 (2007) $1254-1261$

[14] J. R. Hansen, A. C. Hunter, The hydroxylation of steroidal ring D lactones by Cephalosporium aphidicola, Phytochemistry, 49 (1998) 2349-2353

[15] A. C. Hunter. H. Khuenl-Brady, P. Barrett, H. T. Dodd, C. Dedi, Transformation of some $3 \alpha$-substituted steroids by Aspergillus tamarii KITA reveals stereochemical restriction of steroid binding orientation in the minor hydroxylation pathway, J. Steroid Biochem. Mol. Biol., 118 (2010) 171-176

[16] J. W. Blunt, J. B. Stothers, ${ }^{13}$ C NMR of steroids-a survey and commentary, Org. Magn. Reson. 9 (1977) 439-463

[17] D. N. Kirk, H. C. Toms, C. Douglas, K. A. White, A survey of the high-field ${ }^{1} \mathrm{H}$ NMR spectra of steroid hormones, their hydroxylated derivatives and related compounds, J. Chem. Soc., Perkin Trans 2 (1990) 1567-1594

[18] B. Santhamma, K. Acosta, A. Chavez-Riveros, K. Nickisch, A new approach towards the synthesis of drospirenone and steroidal spriolactones. Steroids, 102 (2015) 60-64

[19] A. C. Hunter, E. Coyle, F. Morse, C. Dedi, H. T. Dodd, S.-J. Koussoroplis. Transformation of 5-ene steroids by the fungus Aspergillus tamarii KITA: mixed molecular fate in lactonization and hydroxylation pathways with identification of a putative $3 \beta$-hydroxy- 
steroid dehydrogenase $/ \Delta^{5}-\Delta^{4}$ isomerase pathway. Biochim. Biophys. Acta Mol. Cell Biol. Lipid 1791 (2009) 110-117

[20] A. Świzdor, T. Kołek, A. Panek, A. Białońska, Microbial Baeyer-Villiger oxidation of steroidal ketones using Beauveria bassiana: presence of an $11 \alpha$-hydroxyl group essential to generation of D-homo lactones. Biochim. Biophys. Acta Mol. Cell Biol. Lipid 1811 (2011) $253-262$

[21] K. Watanabe, Effective use of heterologous hosts for characterization of biosynthetic enzymes allows production of natural products and promotes new natural product discovery. Chem. Pharm. Bull., 62 (2014) 1153-1165

[22] Y. Matsuda, T. Awakawa, T. Mori, I. Abe, Unusual chemistries in fungal monoterpenoid biosynthesis, Curr. Opin. Chem. Biol., 31 (2016) 1-7

[23] A. C. Hunter, K. R. Watts, C. Dedi, H. T. Dodd. An unusual ring-A opening and other reactions in steroid transformation by the thermophilic fungus Myceliophthora thermophile. $\mathrm{J}$. Steroid Biochem. Mol. Biol., 116 (2009) 171-17

[24] S. P. Kolet, S. Haldar, S. Niloferjahan, H. V. Thulasiram, Mucor hiemalis mediated 14 $\alpha-$ hydroxylation on steroids: In vivo and in vitro investigations of $14 \alpha$-hydroxylase activity. Steroids, 85 (2014) 6-12

[25] W. Ebrahim, A. H. Aly, V. Wray, P. Proksch, A. Debbab. Unusual octalactones from Corynespora cassiicola, an endophyte of Laguncularia racemosa. Tetrahedron Lett. 54 (2013) 6611-6614 
[26] D-L Zhao, C-L Shao, C-Y Wang, M. Wang, L-J Yang, C-Y Wang. Napthalenones and depsidones from a spong-derived strain of the fungus Corynespora cassiicola. Molecules, 21 (2016) 160

[27] W. Ebrahim, A. H. Aly, A. Mándi, F. Totzke, M. H. G. Kubbutat, V. Wray, W-H Lin, H. Dai, P. Proksch, T. Kurtán, A. Debbab. Decalactone derivatives from Corynesporum cassiicola, an endophytic fungus of the mangrove plant Laguncularia racemosa. Eur. J. Org. Chem., (2012) 3476-3484

[28] Y. Matsuda, T. Awakawa, T. Wakimoto, I. Abe, Spiro-ring formation is catalysed by a multifunctional dioxygenase in austinol biosynthesis, J. Am. Chem. Soc., 135 (2013) $10962-$ 10965

[29] L-F Wu, S. Meng, G-L Tang, Ferrous iron and $\alpha$-ketoglutarate-dependent dioxygenases in the biosynthesis of microbial natural products, Biochimica Biophysica Acta, Proteins and Proteomics, 1864 (2016) 453-470

[30] J. M. Brown, A. D. Conn, G. Pilcher, L. P. Leitã, Y. Meng-Yan. On the strain energy of 5-ring and 6-ring lactones. J. Chem. Soc. Chem. Commun., 23 (1989) 1817-1819

[31] L. Mandolini, Intramolecular reactions of chain molecules. Adv. Phys. Org. Chem, 22 (1987) $1-111$

[32] C. L. Preisig, J. A. Laakso, U. M. Mocek, P. T. Wang, J. Baez, G. Byng, Biotransformations of the cardiovascular drugs mexrenone and canrenone, J. Nat. Prod.,66 (2003) 350-356 
[33] P. Fernandes, A. Cruz, B. Angelova, H. M. Pinheiro, J. M. S. Cabral, Microbial conversion of steroid compounds: recent developments, Enzyme Microbial Technol., 32 (2003) 688-705

[34] S. B. Mahato, S. Garai, Advances in microbial steroid biotransformation, Steroids, 62 (1997) 332-345

[35] B. Pitt, F. Zannad, W. J. Remme, R. Cody, A. Castaigne, A. Perez, J. Palensky, J. Wittes, The effect of spironolactone on morbidity and mortality in patients with severe heart failure, New Engl. J. Med 341 (1999) 709-717

[36] ] B. Pitt, W. Remme, F. Zannad, J. Neaton, F. Martinez, B. Roniker, R. Bittman, S. Hurley, J. Kleiman, M. Gatlin, Eplerenone, A selective aldosterone blocker, in patients with left ventricular dysfunction after myocardial infarction, New Engl. J. Med., 348 (2003) 10391321

[37] B. Lacombe, M. Morei, F. Margottin-Goguet, B. C. Ramirez, Specific inhibition of HIV infection by the action of spironolactone in T cells, J. Virol., 90 (2016) 10972-10980 
Table $1{ }^{13} \mathrm{C}$ NMR data for starting materials determined in $\mathrm{CDCl}_{3}$

\begin{tabular}{|c|c|c|c|c|}
\hline & Compounds & & & \\
\hline & 1 & 2 & 3 & 4 \\
\hline \multicolumn{5}{|l|}{$\begin{array}{l}\text { Carbon } \\
\text { atom }\end{array}$} \\
\hline 1 & 32.62 & 31.94 & 36.48 & 36.73 \\
\hline 2 & 25.95 & 28.92 & 27.26 & 31.20 \\
\hline 3 & 69.77 & 66.29 & 73.34 & 71.08 \\
\hline 4 & 32.58 & 35.55 & 33.66 & 37.68 \\
\hline 5 & 39.40 & 38.47 & 43.96 & 44.17 \\
\hline 6 & 27.92 & 28.12 & 28.11 & 28.25 \\
\hline 7 & 30.42 & 30.52 & 30.47 & 30.58 \\
\hline 8 & 37.85 & 37.89 & 37.81 & 37.88 \\
\hline 9 & 52.93 & 53.07 & 52.89 & 53.05 \\
\hline 10 & 35.06 & 36.08 & 35.46 & 35.48 \\
\hline 11 & 19.73 & 19.75 & 21.49 & 22.02 \\
\hline 12 & 28.64 & 28.68 & 39.20 & 39.27 \\
\hline 13 & 82.66 & 83.49 & 83.35 & 83.50 \\
\hline 14 & 46.34 & 46.33 & 46.15 & 46.25 \\
\hline 15 & 21.58 & 21.59 & 19.75 & 19.76 \\
\hline 16 & 39.30 & 39.32 & 28.62 & 28.62 \\
\hline 17 & 170.84 & 171.67 & 170.68 & 171.85 \\
\hline 18 & 20.11 & 20.16 & 20.13 & 20.12 \\
\hline 19 & 11.19 & 11.05 & 12.04 & 12.15 \\
\hline 20 & 169.88 & $2>$ & 171.60 & \\
\hline 21 & 21.51 & - & 21.45 & \\
\hline
\end{tabular}

Data for compounds 1 and 2 from references [13] and [15] respectively 
Table $2{ }^{13} \mathrm{C}$ NMR data for transformation products

\begin{tabular}{|c|c|c|c|c|}
\hline & Compounds & & & \\
\hline & $\mathbf{5}$ & $\mathbf{6}$ & $\mathbf{7}$ & $\mathbf{8}$ \\
\hline Carbon atom & & & & \\
\hline 1 & 31.86 & 34.44 & 35.88 & 34.37 \\
\hline 2 & 28.60 & 28.27 & 29.69 & 37.70 \\
\hline 3 & 66.09 & 66.04 & 70.62 & 211.80 \\
\hline 4 & 35.45 & 35.76 & 34.37 & 44.36 \\
\hline 5 & 36.98 & 30.36 & 35.88 & 39.93 \\
\hline 6 & 27.86 & 27.92 & 28.02 & 28.22 \\
\hline 7 & 29.88 & 27.73 & 31.05 & 31.36 \\
\hline 8 & 42.48 & 39.91 & 39.88 & 39.83 \\
\hline 9 & 46.63 & 74.55 & 74.45 & 74.31 \\
\hline 10 & 37.87 & 40.61 & 40.10 & 40.17 \\
\hline 11 & 21.65 & 24.46 & 24.47 & 24.14 \\
\hline 12 & 25.91 & 28.71 & 28.72 & 28.68 \\
\hline 13 & 73.31 & 83.48 & 83.33 & 83.07 \\
\hline 14 & 93.17 & 38.47 & 39.88 & 38.05 \\
\hline 15 & 24.41 & 19.56 & 19.62 & 19.64 \\
\hline 16 & 35,91 & 28.45 & 28.14 & 28.34 \\
\hline 17 & 177.71 & 171.76 & 171.67 & 171.45 \\
\hline 18 & 21.20 & 19.41 & 19.36 & 19.36 \\
\hline 19 & 10.78 & 13.25 & 14.28 & 13.44 \\
\hline
\end{tabular}


Figure 1

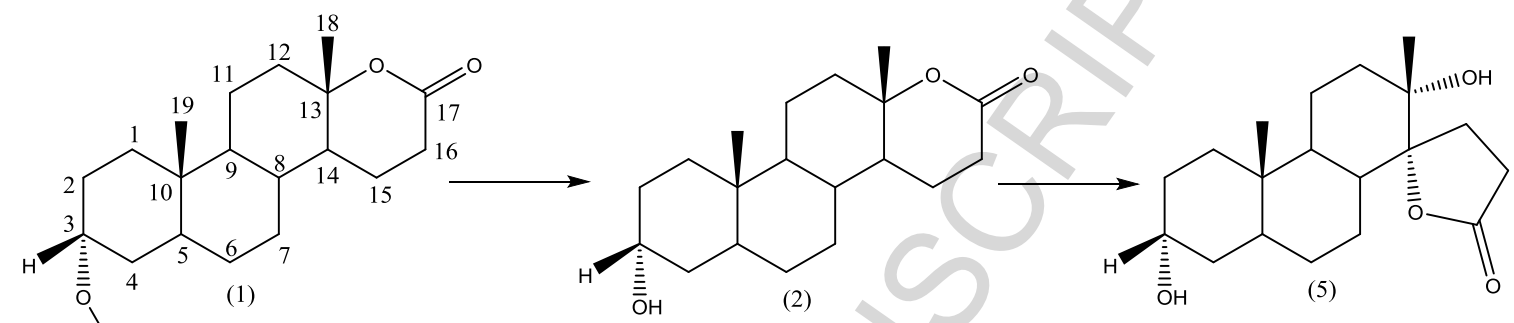

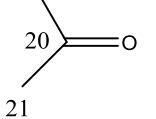
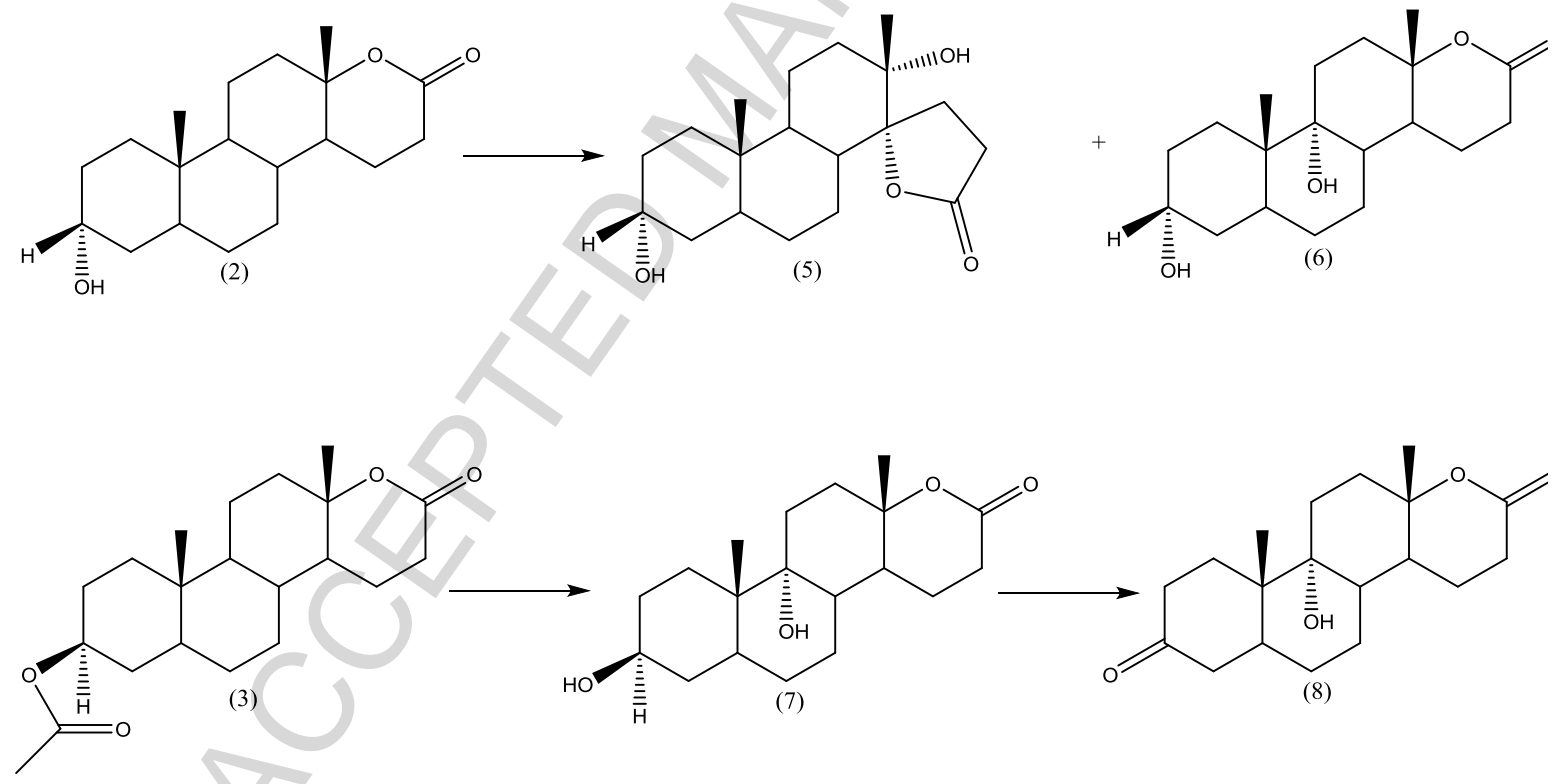

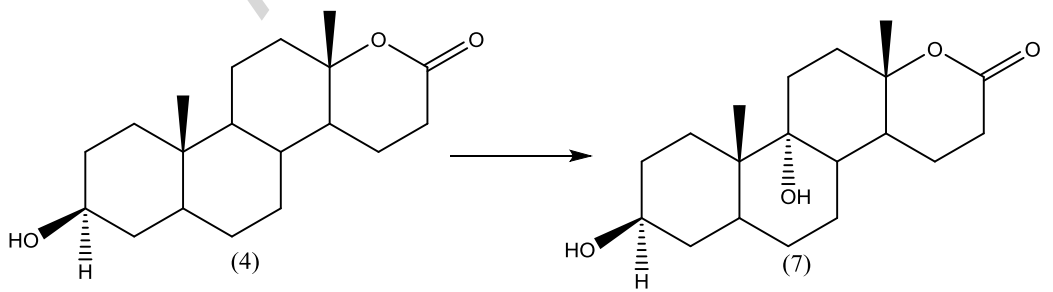


Figure 2.

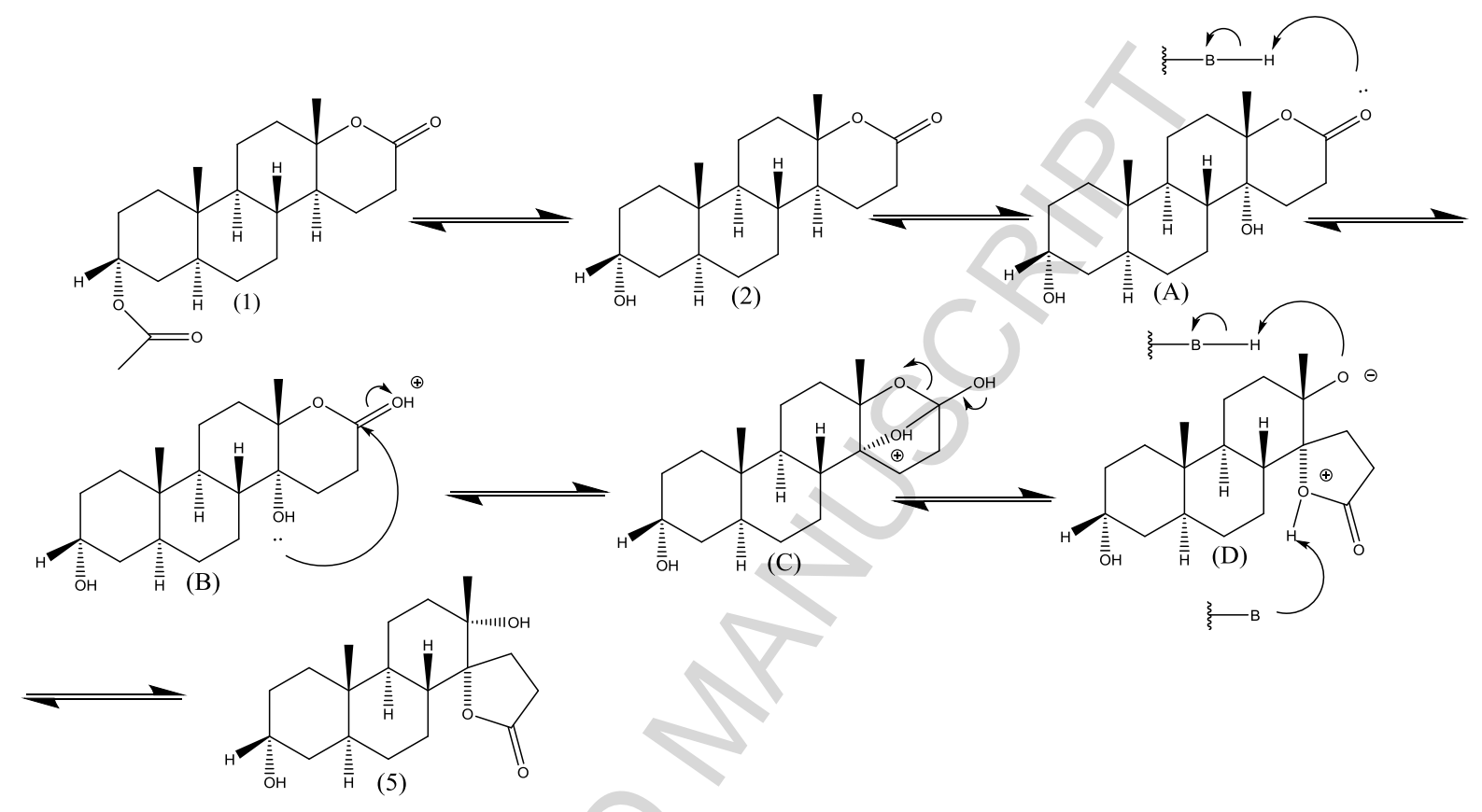


Figure 3.

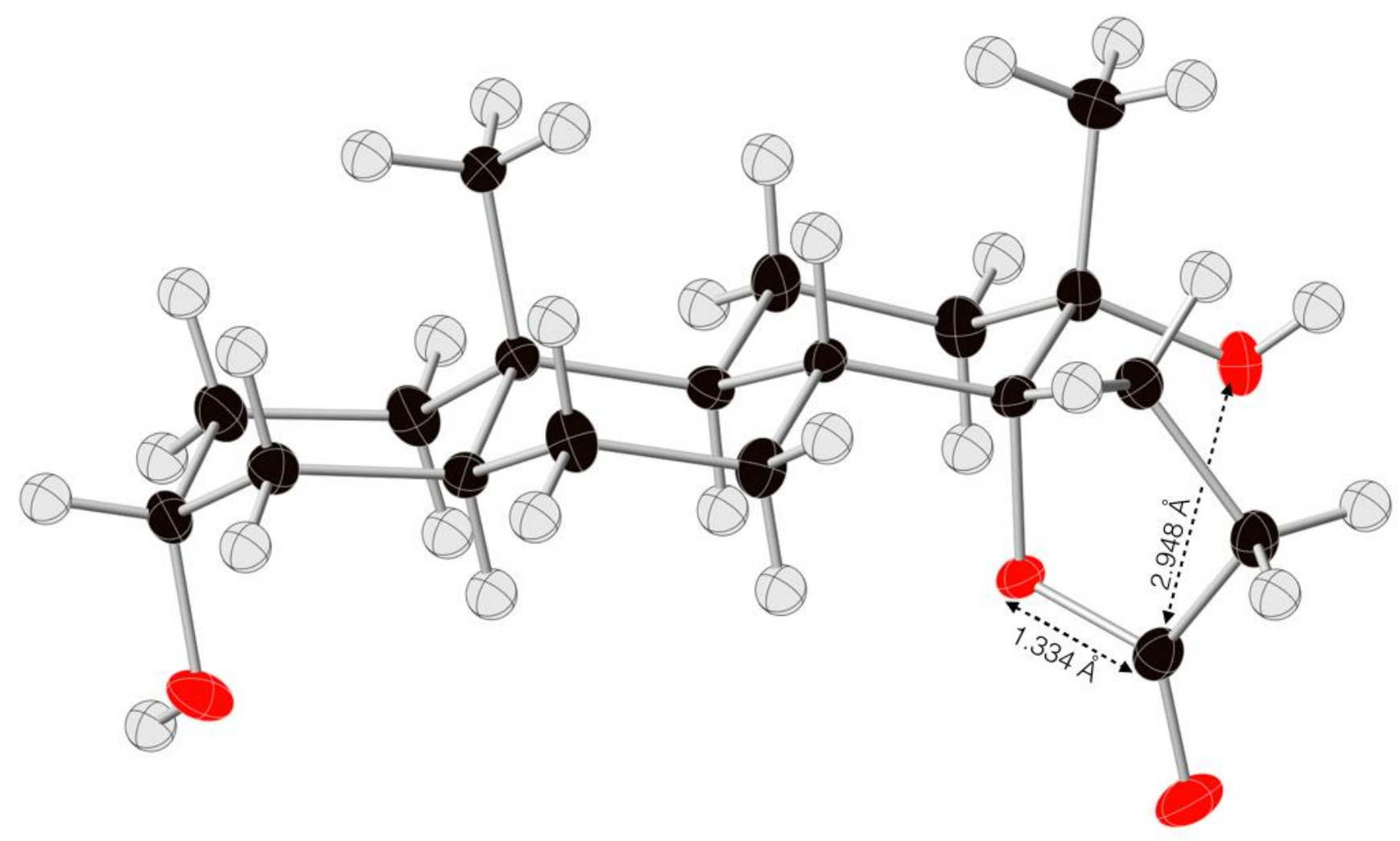


Figure 4

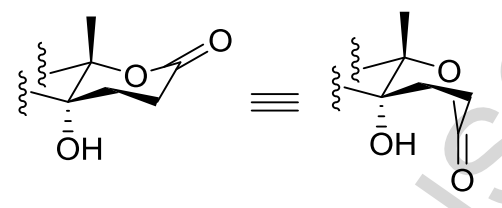

(a)

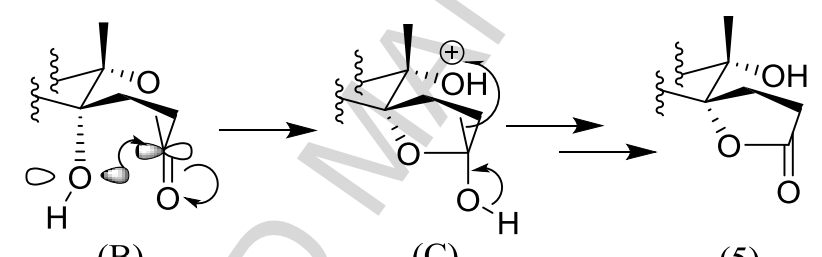

(b) 
Figure legends

Figure 1. Transformation of a series of $3 \alpha-(\mathbf{1}$ and 2$)$ and $3 \beta-(3$ and 4$)$ functionalized steroidal lactones and their products $(\mathbf{2 , 5 , 6 , 7 , 8 )}$ following 5 days incubation with Corynespora cassiicola.

Figure 2. Acid catalysed mechanistic pathway for transesterification mechanism underlying the formation of 5 .

Figure 3. Single X-ray crystal structure of $3 \alpha, 13 \alpha$-dihydroxy-nor-15,16,17-5 $\alpha$-androst-14 $\alpha$ carbolactone 5 with proximity of oxygens attached to ring-D keto-carbon.

Figure 4. (a) Structural comparison of chair conformation and energetically favoured twist chair conformation. (b) Kinetic preorganization promoting formation of the 5-membered lactone 5 . 

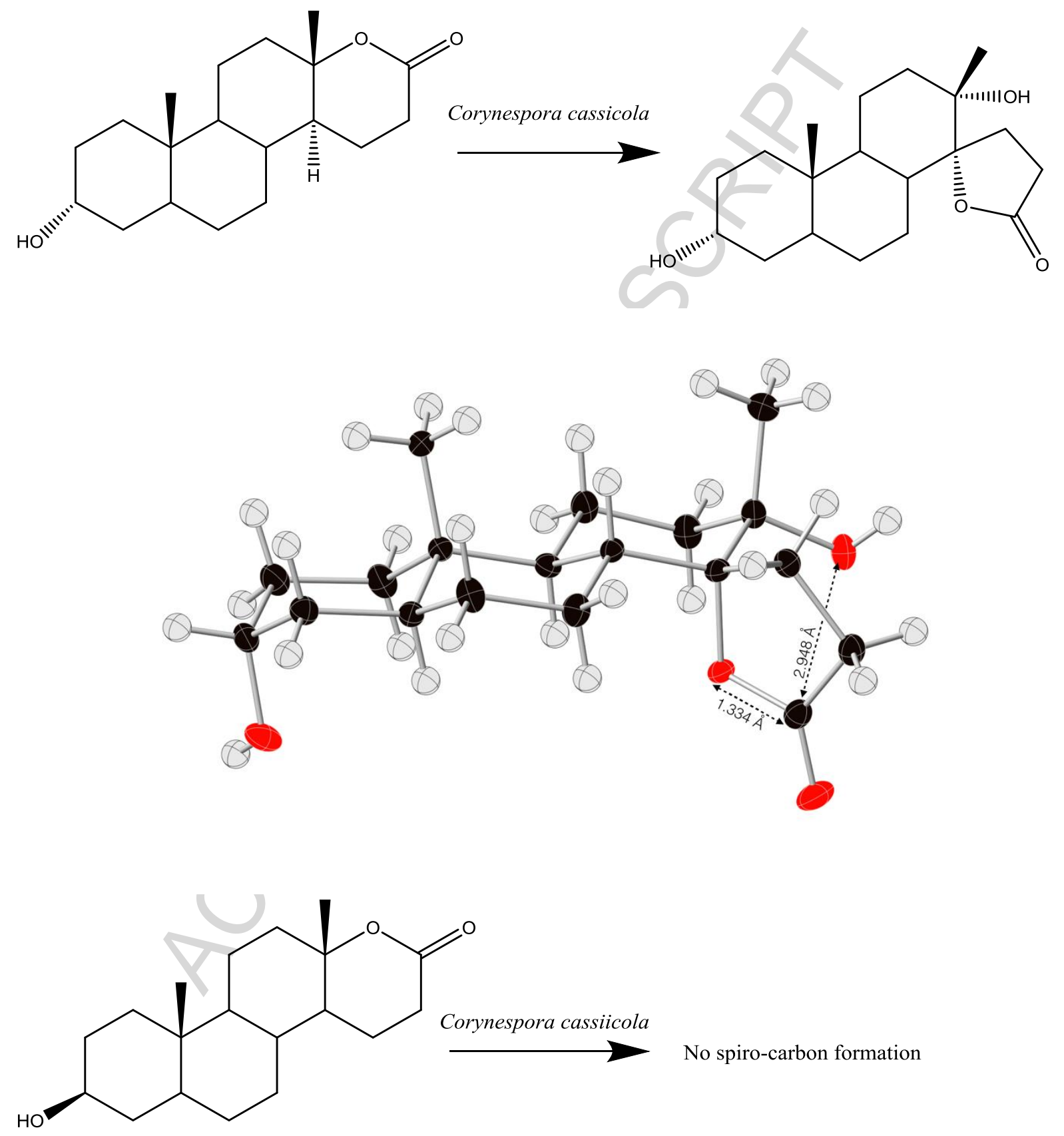

Graphical Abstract 


\section{Highlights of study}

-Novel enzyme driven rearrangement resulting in unique spiro-lactone architecture -Spiro-lactone formation based on rapid two step mechanism -Rearrangement based on C-14 hydroxylation followed by transesterification -Strict stereochemical requirements of C-3 functionality identified for rearrangement 